\title{
An electrochemical immunosensor for the corona virus associated with the Middle East respiratory syndrome using an array of gold nanoparticle-modified carbon electrodes
}

\author{
Laila Ali Layqah $^{1} \cdot$ Shimaa Eissa ${ }^{1}$ (B) \\ Received: 20 November 2018 / Accepted: 27 February 2019 / Published online: 7 March 2019 \\ (C) Springer-Verlag GmbH Austria, part of Springer Nature 2019
}

\begin{abstract}
The Middle East respiratory syndrome corona virus (MERS-CoV) is highly pathogenic. An immunosensor for the determination of MERS-CoV is described here. It is based on a competitive assay carried out on an array of carbon electrodes (DEP) modified with gold nanoparticles. Recombinant spike protein S1 was used as a biomarker for MERS CoV. The electrode array enables multiplexed detection of different CoVs. The biosensor is based on indirect competition between free virus in the sample and immobilized MERS-CoV protein for a fixed concentration of antibody added to the sample. Voltammetric response is detected by monitoring the change in the peak current (typically acquired at a working potential of $-0.05 \mathrm{~V} \mathrm{vs}$. $\mathrm{Ag} / \mathrm{AgCl}$ ) after addition of different concentrations of antigen against MERS-CoV. Electrochemical measurements using ferrocyanide/ferricyanide as a probe were recorded using square wave voltammetry (SWV). Good linear response between the sensor response and the concentrations from 0.001 to 100 ng. $\mathrm{mL}^{-1}$ and 0.01 to 10,000 ng. $\mathrm{mL}^{-1}$ were observed for MERS-CoV and HCoV, respectively. The assay was performed in 20 min with detection limit as low as 0.4 and $1.0 \mathrm{pg} \cdot \mathrm{mL}^{-1}$ for HCoV and MERS-CoV, respectively. The method is highly selective over non-specific proteins such as Influenza A and B. The method is single-step, sensitive and accurate. It was successfully applied to spiked nasal samples.
\end{abstract}

Keywords Corona virus · Voltammetry · Array electrode $\cdot$ Electrochemical biosensor · MERS-CoV $\cdot \mathrm{HCoV} \cdot \mathrm{Multiplexed}$ biosensor $\cdot$ Simultaneous detection $\cdot$ Competitive immunosensor

\section{Introduction}

The Middle East Respiratory Syndrome Corona Virus (MERS-CoV) is one of the highly pathogenic viruses. It causes thousands of serious illness and hundreds of human life losses in Saudi Arabia and all over the world. Human respiratory infections caused by corona viruses $(\mathrm{CoV})$ such as HCoV-229E and HCoVOC43 are known since 1960s [1] and later another few types of $\mathrm{CoV}$ have been discovered such

Electronic supplementary material The online version of this article (https://doi.org/10.1007/s00604-019-3345-5) contains supplementary material, which is available to authorized users.

Shimaa Eissa

seissa@alfaisal.edu

1 Department of Chemistry, Alfaisal University, Al Zahrawi Street, Al Maather, AlTakhassusi Road, Riyadh 11533, Saudi Arabia as SARS-CoV, HCoV NL63 and HCoV HKU1 [2]. Severe respiratory illness in human due to MERS-CoV was first reported in June 2012 at Jeddah hospital in Saudi Arabia. Within short period of time, another patient with acute kidney injury and acute respiratory syndrome was reported in Qatar. In April 2012, two patients were found to be infected with MERS-CoV in Jordan [3]. Since MERS-CoV was identified, it spread over 23 countries. 1936 cases with 690 deaths (35.6\% case fatality rate) have been reported by the WHO caused via MERS-CoV until 27 April 2017 [4]. In South Korea, an outbreak of 180 confirmed MERS-CoV infected cases and 36 deaths were recorded in May and June 2015 [5].

The incubation period of the MERS-CoV varies between 2 and 14 days [6]. Children's, young adult and pregnant women are more susceptible to MERS-CoV [7]. There is strong evidence from the clustering studies for spreading the virus from human-to human. This transmittance might cause mild illness, severe pneumonia, severe respiratory syndrome, multi organ failure [6]. Other symptoms of MERS-CoV infections include 
nausea, fever, anorexia, disseminated intercellular coagulation, vomiting, abdominal pain, diarrhea were also reported [8]. So far, there is no approved vaccine or antiviral therapy for MERS-CoV. MERS-CoV cases must be confirmed by the WHO and Ministry of Health - Saudi Arabia recommended laboratory tests. Real time reverse Transcription PCR (rRTPCR) is recommended by WHO. The suspected cases must be screened by the two qRT-PCR from two specific genome regions and reconfirmed by one qRT-PCR from the positive genome $[9,10]$.

Several other assays for virus detection such as immunofluorescence assay [11], protein microarray assay [12], reverse transcription loop mediated isothermal amplification assay (RT-LAMP) [13, 14], viral plaque assay [15], Hemagglutination assay [15], viral flow cytometry (FCM) [16] and enzyme linked immunosorbent assay (ELISA) [2] can be also used. Despite of the high sensitivity of these methods, they are not suitable for large scale screening for multiple samples because of their high cost and long analysis time. Moreover, these methods needs skilled personal to perform and not suitable for point-of-care testing.

Nanobiotechnology plays a potential role in the clinical applications particularly, in the development of biosensors for the detection of pathogenic microorganisms. Various immunosensors have been reported for the detection of virus using different transducers as better alternative to traditional assays. For instance, the detection of SARSassociated coronavirus (SARS-CoV) in sputum in the gas phase was done by piezoelectric immunosensor. This work was based on the binding of horse polyclonal antibody of SARS-CoV to piezoelectric crystal surface through protein A. The mass of the crystal was changing and shift in the frequency was recorded upon virus binding [17]. Localized surface plasmon coupled fluorescence (LSPCF) fiber-optic biosensor was also developed for the detection of SARS corona virus (SARS-CoV) nucleocapsid protein N. LSP with sandwich immunoassay technique [18]. Label-free RNA amplification and detection method was developed for the detection of MERS-CoV by using bio-optical sensor. The LOD of this assay was 10 times more sensitive than rRT-PCR method [19]. Another new generation system was developed for the robust and facile diagnosis of MERS-CoV based on isothermal rolling circle amplification (RCA) method [20]. However, these methods are still time consuming and costly which limits their wide applications.

Electrochemical immunosensors have become an appealing choice due to their high sensitivity, low-cost, ease of use and possibility of miniaturization. Different electrochemical immunosensors for influenza virus were reported using differential pulse voltammetry (DPV) [21], impedance spectroscopy (EIS) [22], linear sweep voltammetry $[23,24]$, chronoamperometry [25] and cyclic voltammetry
[26]. Electrochemical immunosensor based on reduced graphene oxide (RGO) integrated with microfluidic chip for label-free detection of an influenza virus, H1N1 was also reported showing good selectivity and enhanced detection limit [27]. Human immunodeficiency virus (HIV) was detected using DPV on multi-walled carbon nanotubes (MWCNTs) modified glassy carbon electrode (GCE). Human papillomavirus (HPV) was also detected using glassy carbon electrode modified with graphene/Au nanorod/polythionine via DPV and EIS [28].

Gold nanoparticles (AuNPs) are the most stable metal nanoparticles, due to their unique optical, electronic, catalytic activity, high biocompatibility properties and enhanced electron transfer rate [29]. Therefore, they have shown wide applications in various electrochemical biosensors. Gold nanoparticles can be prepared by the chemical or electrochemical reduction of gold salt [30]. Electrodeposition of AuNPs on the surface of carbon electrodes is very appealing way due to its direct, fast and easier preparation method [31].

To the best of our knowledge, until now, no electrochemical biosensors have been reported for the detection of MERSCoV. In this work, a novel competitive electrochemical immunosensor for MERS-CoV virus detection is developed. Electrodeposition of AuNPs on carbon disposable array electrodes was used for the electrode preparation. The immunosensor is fabricated on array electrodes to enable the simultaneous detection of different types of $\mathrm{CoV}$ virus. This novel competitive immunosensor enables a single step, sensitive and selective detection of MERS-CoV and can be successfully applied in spiked nasal sample. Furthermore, the electrochemical immunosensor provides a low cost, high sensitivity, capability of miniaturization, and on-site high throughput screening of multiple samples.

\section{Experimental section}

\section{Materials and reagents}

Potassium nitrate $\left(\mathrm{KNO}_{3}\right)$, gold (III) chloride solution (30 wt.\% in dilute $\mathrm{HCl}$ ), glutaraldehyde $(25 \%)$, cysteamine hydrochloride, potassium ferrocyanide $\left(\mathrm{K}_{4} \mathrm{Fe}(\mathrm{CN})_{6}\right)$, Potassium ferricyanide $\left(\mathrm{K}_{3} \mathrm{Fe}(\mathrm{CN})_{6}\right)$, bovin serum albumin (BSA) and phosphate buffer saline (PBS) were purchased from Sigma (Ontario, Canada) (http://www.sigmaaldrich. com/canada-english.html). Antigen of $\mathrm{HCoV}(\mathrm{Oc} 43 \mathrm{~N})$ and antibody for $\mathrm{HCoV}$ - Oc43 were purchased from Medix Biochemica (Finland) (https://www.medixbiochemica.com/ en/). MERS-CoV antigen - 725 Spike protein S1 and MERS-CoV antibody were purchased from Sino Biological (Beijing, china) (https://www.sinobiological.com/). Antigen of Influenza A (N1H1) No. J8034 and Influenza B, No. 
J8035 were purchased from biospacific (CA, USA) (https:// www.biospacific.com/).

Antigens and antibodies for both $\mathrm{HCoV}$ and MERS-CoV were prepared and diluted in PBS buffer, $10 \mathrm{mM}, \mathrm{pH}$ 7.4. Glutaraldehyde solution was also prepared in PBS. Milli-Q water was used for the preparation of all the solutions.

\section{Instrumentation}

All the instrumentations and electrodes used in this work are described in detail in the Electronic Supporting Material.

\section{Procedures}

\section{Electrodeposition of gold nanoparticles on the carbon array electrodes}

The deposition of AuNPs on the 8 electrode surfaces were performed using the protocol reported previously [30-34]. The details are included in the Electronic Supporting Material.

\section{Array electrodes modification and multiplexed immunosensor fabrication}

The eight working electrodes of the array sensors were incubated with $50 \mu \mathrm{l}$ of $10 \mathrm{mM}$ solution of cysteamine for $2 \mathrm{~h}$ in water-saturated atmosphere at room temperature. Then, the electrodes were incubated for $1 \mathrm{~h}$ with $50 \mu \mathrm{L}$ of $2.5 \%$ glutaraldehyde in PBS buffer after washing with water. The electrode surfaces were then covered by $10 \mu \mathrm{g} \cdot \mathrm{mL}^{-1}$ solution of human corona virus $(\mathrm{HCoV})$ or MERS-CoV antigens $(10 \mu \mathrm{L}$ of each solution was incubated on different electrode on the same chip) in PBS buffer, $\mathrm{pH} 7.4$ and incubated for $1 \mathrm{~h}$ at room temperature in water saturated atmosphere. Then, electrode was washed extensively with buffer and incubated in $1 \%$ BSA solution for $30 \mathrm{~min}$ to minimize the nonspecific adsorption and block the unreacted aldehyde groups and the free gold surface. Finally, the modified electrodes (immunosensors) were rinsed extensively by PBS buffer to remove the excess BSA and used directly for the detection experiments or stored at $4{ }^{\circ} \mathrm{C}$ in buffer until further use. In the current configuration, 8 electrodes were used. Two control electrodes for comparative purposes were prepared by immobilizing BSA instead of the target antigens. Four electrodes were used for MERS-CoV antigen and 2 electrodes were used for $\mathrm{HCoV}$ antigen. This enables the duplicate measurements for each sample and also testing the cross reactivity on the same chip. The 8 electrodes can be also used in the future to immobilize 8 different $\mathrm{COV}$ antigens for more multiplexed detection.

\section{Electrochemical measurements}

Square wave voltammetry measurements (SWV) were recorded by scanning from 0.4 to $-0.3 \mathrm{~V}$, amplitude: $20 \mathrm{mV}$, frequency: $25 \mathrm{~Hz}$, and step potential: $-5 \mathrm{mV}$. Base-line corrections were done for all the SWV data. The measurements for the calibration plot were acquired at a working potential of $-0.05 \mathrm{~V}$ vs. $\mathrm{Ag} / \mathrm{AgCl}$.

\section{Competitive voltammetric detection of human corona virus $(\mathrm{HCOV})$ and MERS - CoV}

Indirect competitive assay using a fixed concentration of antibody was performed for $\mathrm{HCoV}$ and MERS-CoV free analyte. After the immobilization of $\mathrm{HCoV}$ and MERS$\mathrm{CoV}$ antigens on the working electrodes, each modified electrode on the chip was incubated with a mixture containing different concentrations of free $\mathrm{HCoV}$ or MERS$\mathrm{CoV}$ antigens in the range of $1 \mathrm{pg} \cdot \mathrm{mL}^{-1}-10 \mu \mathrm{g} \cdot \mathrm{mL}^{-1}$ and $10 \mu \mathrm{g} . \mathrm{mL}^{-1}$ solution of $\mathrm{HCoV}$ antibody for $20 \mathrm{~min}$ (the mixture of each antigen with its antibody was prepared off the chip in an Eppendorf Tube and $10 \mu \mathrm{L}$ of each mixture were immediately incubated on the corresponding modified electrode surface). All the electrochemical measurements were taken in $5 \mathrm{mM}$ solution (1:1 ratio) of mixture of ferrocyanide/ferricyanide $\left(\left[\mathrm{Fe}(\mathrm{CN})_{6}\right]^{3-/ 4-}\right)$ in $0.1 \mathrm{M}$ PBS, $\mathrm{pH}$ 7.4. The COV immunosensor response was calculated as $\left(\mathrm{I}^{\mathrm{o}}-\mathrm{I}\right) / \mathrm{I}^{\mathrm{O}} \%$, where $\left(\mathrm{I}^{\mathrm{O}}\right)$ is the SWV current measured at the antigen-modified electrodes after blocking with $1 \%$ BSA and (I) is the current measured after the immunosensor was incubated with a mixture of $\mathrm{HCoV}$ antibody or MERS-CoV antibody with different concentrations of free analyte of $\mathrm{HCoV}$ or MERS-CoV.

\section{Optimization of the experimental conditions}

\section{Concentration of antibody}

The concentration of antibody is critically important for immunosensor performance. Various concentrations of $\mathrm{HCoV}$ and MERS-CoV antibodies $(10 \mu \mathrm{L}$ of each antibody solution was incubated on its specific electrode) were tested by incubation with the antigens-modified electrodes in order to achieve the best performance of the immunosensor.

\section{Binding time}

At the optimized concentration of antibodies $\left(10 \mu \mathrm{g} \cdot \mathrm{mL}^{-1}\right)$, we changed the incubation time at different points $(5,10,15$, 20, 30, 40, and $60 \mathrm{~min}$ ) and the SWV measurements were recorded in $5 \mathrm{mM}\left[\mathrm{Fe}(\mathrm{CN})_{6}\right]^{3-/ 4}$ solution. 


\section{Spiked nasal fluid testing}

Artificial nasal fluid sample was used to test $\mathrm{HCoV}$ and MERS-CoV sensor. Different concentrations of $\mathrm{HCoV}$ and MERS-CoV solutions of $10 \mu \mathrm{L}$ of $\left(0.1 \mathrm{ng} \cdot \mathrm{mL}^{-1}, 1 \mathrm{ng} \cdot \mathrm{mL}^{-1}\right.$, $10 \mathrm{ng} \cdot \mathrm{mL}^{-1}$ ) spiked in 1:100 diluted nasal fluid were mixed with $10 \mu \mathrm{L}$ of $10 \mu \mathrm{g} \cdot \mathrm{mL}^{-1}$ of the antibodies solutions. Then, $10 \mu \mathrm{L}$ of each mixture were applied separately to the surface of the working electrodes containing the $\mathrm{HCoV}$ and MERS $\mathrm{CoV}$ antigens and incubated at room temperature for $20 \mathrm{~min}$.

\section{The selectivity experiments}

It is important to study the selectivity of the immunosensor. This purpose is achieved by using different nonspecific proteins such as Flu A and Flu B antigens. It's performed by mixing $20 \mu \mathrm{L}$ of $20 \mathrm{ng} \cdot \mathrm{mL}^{-1}$ of Flu A or Flu B antigens with $20 \mu \mathrm{L}$ of $20 \mu \mathrm{g} \cdot \mathrm{mL}^{-1} \mathrm{HCoV}$ antibody, and mixing $20 \mu \mathrm{L}$ of $20 \mathrm{ng} \cdot \mathrm{mL}^{-1}$ of Flu A or B antigens with $20 \mu \mathrm{L}$ of $20 \mu \mathrm{g} \cdot \mathrm{mL}^{-1}$ MERS-CoV antibody. Then, each mixture is applied separately on the $\mathrm{HCoV}$ and MERS-CoV immunosensors and incubated for $20 \mathrm{~min}$. SWV measurements were recorded after washing the immunosensor with PBS buffer pH 7.4.

\section{Results and discussion}

\section{Working principle of the immunosensor}

Scheme 1 illustrates the preparation of the MERS-CoV immunosensor and the detection process. The biosensor consists of a competitive immunoassay carried out on a DEP array electrodes nanostructured with gold nanoparticles to enable the multiplexed detection of different CoV. MERS-CoV and $\mathrm{HCoV}$ antigens were used for proof of concept; however, the 8 electrodes can be also used to immobilize 8 different $\mathrm{COV}$ antigens for more multiplexed detection in the future. And further increase of the number of the electrodes on the array chip will allow the high throughput screening of many samples (hundreds) in one go which will significantly reduce the cost and the time of the overall assay. It is worth noting that the cost of the used screen printed array electrode is very low compared with the cost of single 8 electrodes.

Here, we used MERS-CoV recombinant spike protein S1 (Human betacoronavirus 2c EMC/2012) as a biomarker for the sensor construction. This protein comprises 719 amino acids and has a predicted molecular weight of $79.9 \mathrm{kDa}$. The biosensor is based on the indirect competition between the free virus in the sample and immobilized MERS-CoV protein for fixed concentration of added antibody to the sample. The detection was achieve by measuring the reduction peak current of ferro/ferricyanide redox couple after each step. The binding of the antibody to the immobilized protein would lead to a decrease in the SWV reduction peak current. This reduction in the peak current is attributed to the coverage of the electrode surface with the bulky sized antibodies (the antibodies in general have a molecular weight of approximately $150 \mathrm{kDa}$ ). This coverage of the surface with the antibody retards the access of the ferro/ferri cyanide redox couple to the conductive surface and therefore reduces the electron transfer efficiency which in turn leads to a decrease in the current. The sensor
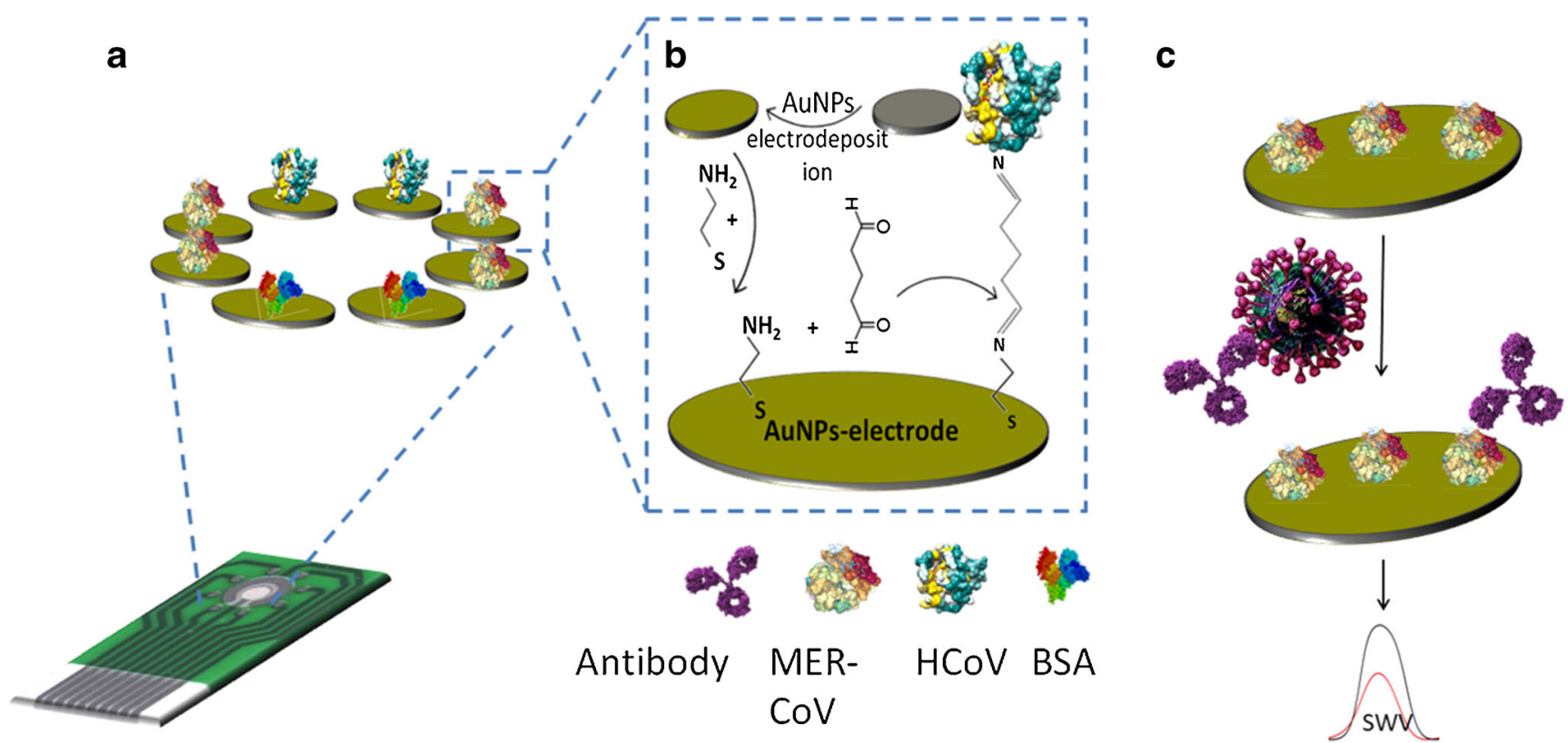

Scheme 1 COV immunosensor array chip (a). The immunosensor fabrication steps (b), the detection process of the competitive immunosensor for the virus (c) 
response is then detected by monitoring the change in the peak current upon adding different concentrations of the MERS-CoV antigen.

\section{Scanning electron microscopy (SEM) characterization of the deposition of AuNPs on the array electrode surface}

The surface of the carbon electrode chip was modified using AuNPs in order to enhance the electron transfer rate and provide higher surface area. The high surface area leads to immobilization of higher number of immobilized biomolecules which improves the biosensor response signal.

The deposition of AuNPs on the 8 array electrodes chip was done using the protocol reported previously [32-36]. This protocol has been highly successful in producing homogeneous layer of particles on different surfaces such as graphene and gold. First, the electroreduction of gold chloride salt was performed using different $\mathrm{CV}$ cycles in order to optimize the deposition. Figure 1a and b show the SEM images for the carbon array electrode surface modified with $20 \mathrm{CV}$ scans at different magnifications, whereas Fig. 1c and d show the surface modified with $30 \mathrm{CV}$ scans. As shown from the SEM characterization, homogenous layer of spherical particles of gold was obtained with average diameter of $50 \mathrm{~nm}$ when the electrodes were modified with $20 \mathrm{CV}$ scans; however, with increasing the number of CV scans than 20, more dense and aggregated particles were observed. Thus, $20 \mathrm{CV}$ scans were chosen for the deposition in order to avoid the aggregation of particles which can reduce the surface area and the reproducibility of the sensors.
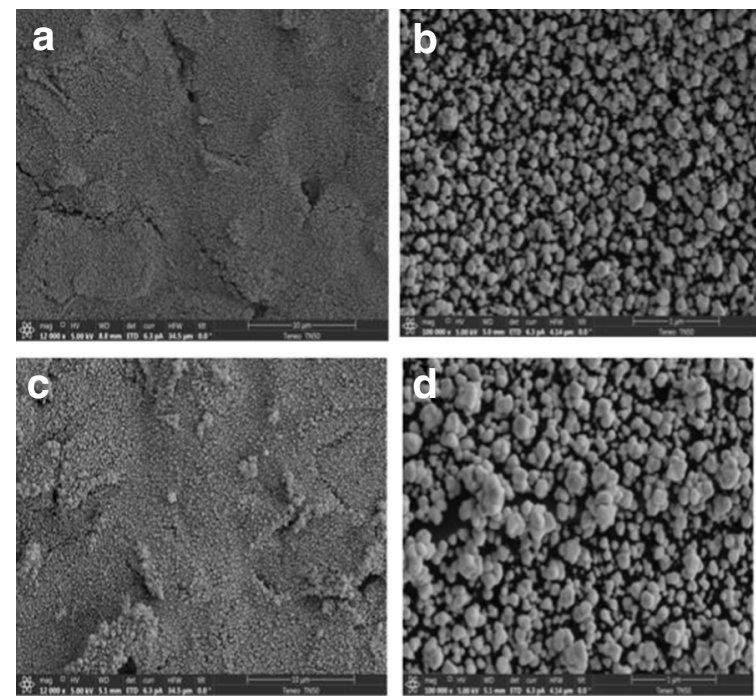

Fig. 1 Scanning electron microscopic images of, AuNPs deposited on electrodes using $20 \mathrm{CV}$ scans at 12000x magnification (a) and 100,000x magnification (b); the AuNPs deposited using $30 \mathrm{CV}$ scans at $12000 \mathrm{x}$ magnification (c) and 100,000x magnification (d). Characterization of MERS- CoV immunosensor fabrication step (e). Square wave

\section{Characterization of the MERS-CoV biosensor fabrication steps}

The characterization of the immunosensor was performed by measuring the SWV of the DEP array electrodes after AuNP deposition, cysteamine incubation and immobilization of the MERS -CoV antigen and blocking by BSA. Square wave voltammetry was utilized to characterize the stepwise modification of the antigen-modified electrodes. Figure 1e shows the SWV in ferro/ferricyanide redox solution for the bare DEP carbon array electrodes before and after each modification step. A well-defined sharp SWV cathodic peak for the reduction of the redox molecules was observed at the bare carbon electrode. Upon the AuNPs deposition on the working electrode surface via the electroreduction of gold salt, the peak current significantly increased. This is due to the increase in the surface area and electron transfer rate of the AuNPsmodified electrodes compared with the carbon. The reduction peak current was then increased after the cysteamine assembly on the AuNP/ DEP array electrodes. This can be attributed to the electrostatic attraction of the redox anions to the positive amine terminals of the cysteamine which led to the elevation of the current. Then, after the activation with gluteraldehyde and MERS-CoV antigen immobilization, the current was decreased. This decrease in the peak current is due to the barriers created on the electrode surface because of the bulky protein which retards the redox molecules to reach surface. This implies the successful covalent attachment of the antigen by reaction of the amino groups of the protein with the terminal aldehyde groups on the electrode surface forming imide bond. In order to confirm the multiplexing capability of the

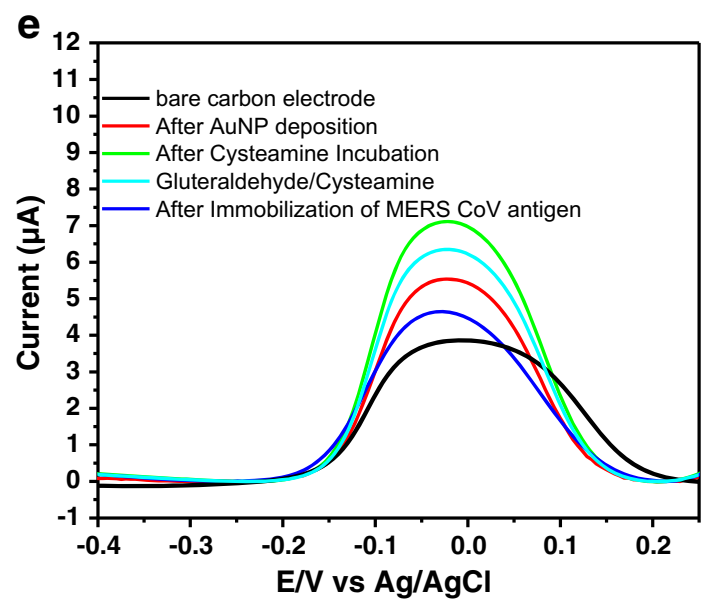

voltammetry in ferro/ferricyanide redox couple of the bare carbon array electrodes (black), after AuNPs electrodeposition using $20 \mathrm{CV}$ scans (red), after cysteamine attachment (green), after gluteraldehyde activation (cyan) and after immobilization of MERS-CoV (blue) antibody 
fabricated biosensor, we immobilized different antigens for different types of $\mathrm{CoV}$ such as MERS-CoV and $\mathrm{HCoV}$.

\section{Optimization of the assay}

\section{Antibody concentration optimization}

It is highly important to study the effect of the antibody concentration that we will be used for the competitive assay in order to get the best sensor response. Figure $2 \mathrm{a}$ shows the biosensor response (the percentage change in the SWV reduction current before and after incubating the antigen-modified electrodes with different concentrations of antibodies in the range of $0.5 \mu \mathrm{g} \cdot \mathrm{mL}^{-1}$ to $60 \mu \mathrm{g} \cdot \mathrm{mL}^{-1}$ ). As can be clearly seen, the response signal increased with increasing the concentration of the antibody until $10 \mu \mathrm{g} \cdot \mathrm{mL}^{-1}$ after which a plateau was reached. $10 \mu \mathrm{g} \cdot \mathrm{mL}^{-1}$ was chosen as the optimum concentration for the subsequent experiments.

\section{Binding time optimization}

It is also very important to study the binding time of the detection method in order to achieve the highest sensor response in the shortest time. Figure $2 \mathrm{~b}$ and $\mathrm{c}$ show the sensor response signals measured after incubating the MERS-CoV and $\mathrm{HCoV}$ -modified electrodes with $10 \mu \mathrm{g} . \mathrm{mL}^{-1}$ of the respective antibodies at different time points. The maximum response was reached at $20 \mathrm{~min}$ for both $\mathrm{HCoV}$ and MERS-CoV indicating the saturation of the surface with the maximum number of antibody molecules.

\section{Competitive detection of MERS CoV and human corona virus ( $\mathrm{HCoV})$}

At the optimum conditions $\left(10 \mu \mathrm{g} \cdot \mathrm{mL}^{-1}\right.$ of the fixed antibody concentration and 20 min incubation time) we have performed the experiments to study the detection range of the
MERS-CoV and $\mathrm{HCoV}$ antigens. In each sample, a certain concentration of each antigen is mixed with $10 \mu \mathrm{g} \cdot \mathrm{mL}^{-1}$ of its specific antibody and incubated immediately on the corresponding electrode on the array chip. After washing, the electrodes were measured using SWV in ferro/ferricyanide redox couple. As shown in Fig. 3a and b, the SWV peak decreases after the incubation with the mixture due to the binding affinity of the antibody to the antigen immobilized on the surface causing a blocking effect because of the bulky antibody that retards the electron transfer and thus deceases the current as explained above.

Figure $3 \mathrm{c}$ and $\mathrm{d}$ show the sensor responses after incubation with different concentrations of proteins from 0.001 to 10,000 ng. $\mathrm{mL}^{-1}$. The calibration plots give good linear relationship between the sensor response and the concentrations from 0.001 to $100 \mathrm{ng} \cdot \mathrm{mL}^{-1}$ and 0.01 to $10,000 \mathrm{ng} \cdot \mathrm{mL}^{-1}$ for MERS-CoV and $\mathrm{HCoV}$, respectively indicating a wide detection range. The linear regression equations of the lines were: $\left(\mathrm{I}^{\mathrm{O}}-\mathrm{I}\right) / \mathrm{I}^{\mathrm{O}} \%=18.84+-8.0 \log \mathrm{C}\left[\mathrm{ng} \cdot \mathrm{mL}^{-\mathbf{1}}\right], \mathrm{R}=0.977$ for MERS-CoV and $\left(\mathrm{I}^{\mathrm{o}}-\mathrm{I}\right) / \mathrm{I}^{\mathrm{o}} \%=17.59+-3.86 \log \mathrm{C}\left[\mathrm{ng} \cdot \mathrm{mL}^{-\mathbf{1}}\right]$, $\mathrm{R}=0.970$ for $\mathrm{HCoV}$. Limits of detection (LOD) were calculated as the concentration that leads to $95 \%$ of the maximum signal to be $1.04 \mathrm{pg} \cdot \mathrm{mL}^{-1}$ and $0.4 \mathrm{pg} . \mathrm{mL}^{-1}$ for MERS-CoV and $\mathrm{HCoV}$, respectively.

This indicates high sensitivity of the multiplexed immunosensor for MERS- $\mathrm{CoV}$ and $\mathrm{HCoV}$ which we attribute it to the highly conductivity of the AuNPs- modified electrodes which leads to an increase of the electrode surface area and electron transfer efficiency, successful covalent immobilization of antigens on the surface as well as the high sensitivity of the SWV technique. Compared with the reported ELISA for MERS CoV [2], our detection limit is lower than the ELISA (1 ng.mL) indicating the good sensitivity of our sensor. The limit of quantification of the reported isothermal amplification platform for MERS strands $\left(20 \mathrm{nt}\right.$ ) was $10 \times 10^{-12}$ M, $6 \times 109$ copies per device which was comparable with the RT-PCR method. Our electrochemical sensor is also user-
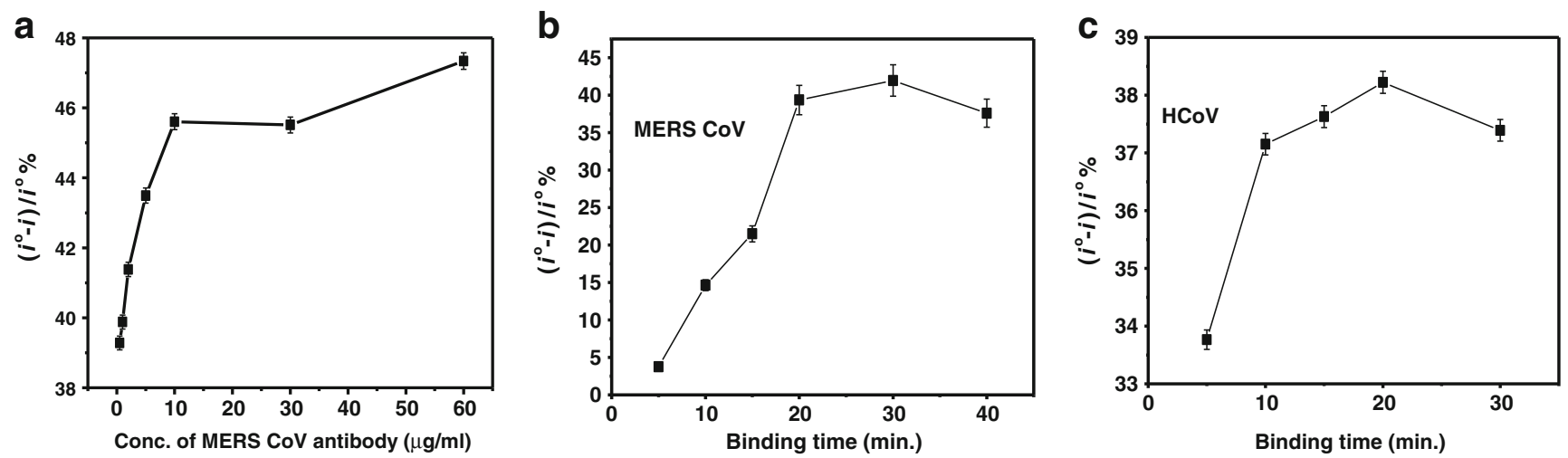

Fig. 2 a Optimization of MERS-CoV antibody concentration, $\mathbf{b}$ Effect of MERS-CoV immunosensor binding time between antibody and immobilized antigen. $\mathbf{c}$ Effect of $\mathrm{HCoV}$ immunosensor binding time between antibody and immobilized antigen. $n=3$ 
Fig. 3 a SWV before and after the competition step of MERS$\mathrm{CoV}$ immunosensor and $\mathbf{b} \mathrm{SWV}$ before and after the competition step of HCoV immunosensor. The calibration plots were based on the $\%$ change of the SWV peak currents $\left(\mathrm{I}^{\mathrm{O}}-\mathrm{I}\right) / \mathrm{I}^{\mathrm{o}} \%$, where $\mathrm{I}^{\mathrm{o}}$ is current measured at the antigenmodified electrodes after blocking with $1 \%$ BSA and I is the current measured after incubation with the sample mixed with the antibody, versus the logarithm of the different concentrations of MERS-CoV (c) or $\mathrm{HCOV} \mathrm{(d)} \mathrm{antigens.} n=3$, the current of the calibration plot was acquired at $-0.05 \mathrm{~V}$
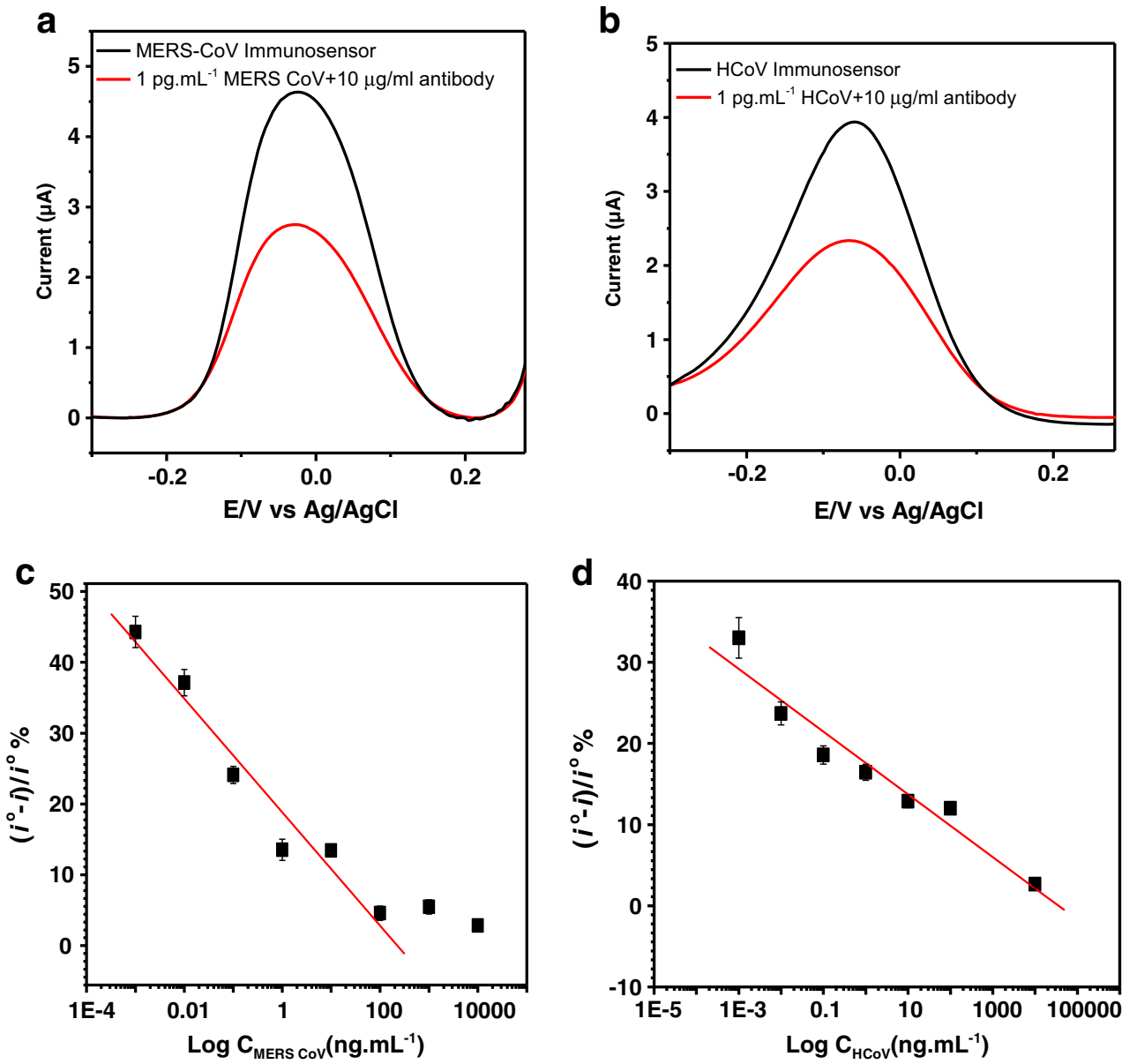

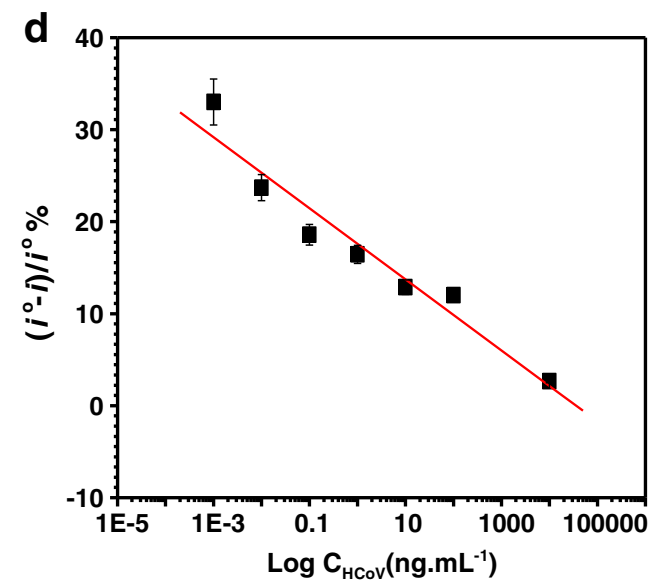

friendly and less costly than quantitative real-time RT-PCR which makes it more suitable in areas where resources and expertise could be limited.

The array immunosensor accuracy was also tested by performing triplicate experiments for each antigen. The relative standard deviations of the results ranged from $3.0-6 \%$ implying very good reproducibility of the immunosensor.

The high sensitivity and fast response along with the low cost and capability of miniaturization of this method make it excellent way for MERS- CoV detection.

\section{Selectivity of the immunosensor}

The selectivity of the MERS-CoV and $\mathrm{HCoV}$ immunosensor was studied against other unrelated virus proteins such as FluA and FluB proteins in order to confirm the selectivity of the immunosensor response. The array immunosensor was therefore incubated with FluA and FluB proteins, and then the sensor response was measured after washing with PBS buffer. As shown in Fig. 4a and b the immunosensor responses for MERS-CoV and $\mathrm{HCoV}$ proteins was remarkably lower than
Fig. 4 a MERS-CoV immunosensor response against 10 ng.mL ${ }^{-1}$ of MERS-CoV, Flu A, Flu B and control electrode. b $\mathrm{HCoV}$ immunosensor response against 10 ng. $\mathrm{mL}^{-1}$ of $\mathrm{HCoV}$, Flu A, Flu B and control. $n=3$

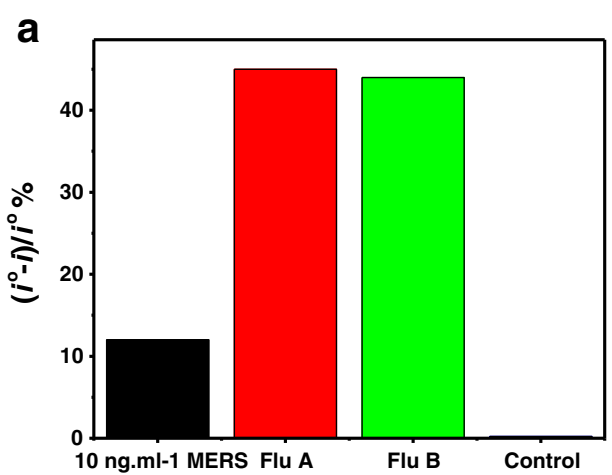


Table 1 Application of MERS-CoV and $\mathrm{HCoV}$ immunosensor in spiked nasal samples. $n=3$

\begin{tabular}{llllllcc}
\hline $\begin{array}{l}\text { Spiked HCoV } \\
\text { ng.mL }\end{array}$ & Conc. found & Recovery $\%$ & RSD \% & $\begin{array}{l}\text { Spiked MERS- CoV } \\
\text { ng.mL } \mathrm{mL}^{-1}\end{array}$ & Conc. found & Recovery \% \\
\hline 10 & 8.90 & 89 & 5.3 & 10 & 10.43 & 104 \\
1 & 0.90 & 90 & 3.2 & 1 & 0.956 & 95 & 4.9 \\
0.1 & 0.097 & 97 & 6.2 & 0.1 & 0.108 & 108 & 4.0 \\
\hline
\end{tabular}

the non-specific proteins that is attributed to the selectivity of the sensor towards their respective proteins. The high signals for the non-specific proteins indicated that no competition was taking place and therefore, maximum number of antibody molecules binds to the surface. However, in the case of the specific proteins, a competition takes place leading to less amount of antibody available for binding with the antigen immobilised on the surface. We have also tested a control electrode on which BSA protein was immobilised on the surface instead of the specific antigens. No significant responses were obtained for the control electrodes indicating that there is no non-specific adsorption on the sensors. These results indicate appropriate selectivity of the biosensor. Moreover, the simultaneous detection of the two proteins (MERS-CoV and $\mathrm{HCoV}$ ) was also confirmed by mixing the two proteins and incubation on the entire sensor surface. In this case, signals were obtained for both MERS-CoV and HCoV electrodes indicating the possible applicability of the sensor for simultaneous detection of multiple types of $\mathrm{CoV}$. The relative standard deviations of the measurements on different sensors were around $5 \%$ indicating the good repeatability of the sensors. The sensors were also stable for around 2 weeks with only around $2 \%$ change in the current indicating good stability of the assay.

\section{Spiked nasal samples analysis}

In order to test the feasibility of applying the developed competitive immunosensor for the detection of the virus in biological fluids, artificial nasal samples spiked with MERS-CoV and $\mathrm{HCoV}$ antigens were analysed using our immunosensor. As shown in Table 1, the spiked samples were tested in each case showed high recovery percentages ranging from 89 to $97 \%$ for the $\mathrm{HCoV}$ and 95 to $108 \%$ for MERS-CoV. These results indicate the possible application of our sensor in real samples. The relative standard deviations were also found to be in the range from 3 to $6 \%$ indicating good precision of the assay.

\section{Conclusion}

A novel competitive electrochemical immunosensor for MERS$\mathrm{CoV}$ which was carried out on a DEP array electrodes nanostructured with gold nanoparticles was developed. The detection relied on the indirect competition between the free virus in the sample and immobilized MERS-CoV protein for fixed concentration of added antibody to the sample. The sensor response was detected by monitoring the change in the peak current of the SWV signal upon adding different concentrations of the MERS-CoV antigen. This immunosensor showed low detection limit, high degree of selectivity against other non-specific proteins (Flu A and Flu B) and acceptable stability. The sensitivity of MERS-CoV immunosensor is attributed to the utilization of AuNP modified carbon array electrodes which lead to increased electron transfer efficiency and electrode surface area. Furthermore, the use of disposable DEP array electrode reduces the cost of the assay and enabled the multiplexed detection of MERS-CoV and HCoV simultaneously. Finally, the competitive immunosensor was successfully used to detect MERS-CoV and $\mathrm{HCoV}$ proteins in spiked nasal samples showing good recovery percentages. Collection of patient samples and healthy samples will be done in the future for further testing of the sensor and the results will be compared with the standard methods used currently in the hospitals such as RT PCR.

Compliance with ethical standards The author(s) declare that they have no competing interests.

Publisher's note Springer Nature remains neutral with regard to jurisdictional claims in published maps and institutional affiliations.

\section{References}

1. Hamre D, Procknow JJ (1966) A new virus isolated from the human respiratory tract. Proc Soc Exp Biol Med 121:190-193

2. Chen Y, Chan KH, Kang Y, Chen H, Luk HK, Poon RW, Chan JF, Yuen KY, Xia N, Lau SK, Woo PC (2015) A sensitive and specific antigen detection assay for Middle East respiratory syndrome coronavirus. Emerg Microbes Infect 4:e26. https://doi.org/10.1038/emi. 2015.26

3. Hijawi B, Abdallat M, Sayaydeh A, Alqasrawi S, Haddadin A, Jaarour N, Alsheikh S, Alsanouri T (2013) Novel coronavirus infections in Jordan, April 2012: epidemiological findings from a retrospective investigation. East Mediterr Health J 19(Suppl 1): S12-S18

4. Zhao J, Alshukairi AN, Baharoon SA, Ahmed WA, Bokhari AA, Nehdi AM, Layqah LA, Alghamdi MG, Al Gethamy MM, Dada AM, Khalid I, Boujelal M, Al Johani SM, Vogel L, Subbarao K, 
Mangalam A, Wu C, Ten Eyck P, Perlman S (2017) Recovery from the Middle East respiratory syndrome is associated with antibody and T-cell responses. Sci Immunol 2:eaan5393. https://doi.org/10. 1126/sciimmunol.aan5393

5. Park HY, Lee EJ, Ryu YW, Kim Y, Kim H, Lee H, Yi SJ (2015) Epidemiological investigation of MERS-CoV spread in a single hospital in South Korea, May to June 2015. Euro Surveill 20:1-6

6. Assiri A, Al-Tawfiq JA, Al-Rabeeah AA, Al-Rabiah FA, Al-Hajjar S, Al-Barrak A, Flemban H, Al-Nassir WN, Balkhy HH, AlHakeem RF, Makhdoom HQ, Zumla AI, Memish ZA (2013) Epidemiological, demographic, and clinical characteristics of 47 cases of Middle East respiratory syndrome coronavirus disease from Saudi Arabia: a descriptive study. Lancet Infect Dis 13:752761. https://doi.org/10.1016/s1473-3099(13)70204-4

7. Memish ZA, Al-Tawfiq JA, Assiri A, AlRabiah FA, Al Hajjar S, Albarrak A, Flemban H, Alhakeem RF, Makhdoom HQ, Alsubaie S, Al-Rabeeah AA (2014) Middle East respiratory syndrome coronavirus disease in children. Pediatr Infect Dis J 33:904-906. https:// doi.org/10.1097/inf.0000000000000325

8. Memish ZA, Zumla AI, Al-Hakeem RF, Al-Rabeeah AA, Stephens GM (2013) Family cluster of Middle East respiratory syndrome coronavirus infections. N Engl J Med 368:2487-2494. https://doi. org/10.1056/NEJMoa1303729

9. Corman VM, Muller MA, Costabel U, Timm J, Binger T, Meyer B, Kreher P, Lattwein E, Eschbach-Bludau M, Nitsche A, Bleicker T, Landt O, Schweiger B, Drexler JF, Osterhaus AD, Haagmans BL, Dittmer U, Bonin F, Wolff T, Drosten C (2012) Assays for laboratory confirmation of novel human coronavirus (hCoV-EMC) infections. Euro Surveill 17:20334

10. Mahallawi WH (2018) Case report: detection of the Middle East respiratory syndrome corona virus (MERS-CoV) in nasal secretions of a dead human. J Taibah Univ Med Sci 13:302-304. https://doi. org/10.1016/j.jtumed.2017.07.004

11. Buchholz U, Muller MA, Nitsche A, Sanewski A, Wevering N, Bauer-Balci T, Bonin F, Drosten C, Schweiger B, Wolff T, Muth D, Meyer B, Buda S, Krause G, Schaade L, Haas W (2013) Contact investigation of a case of human novel coronavirus infection treated in a German hospital, October-November 2012. Euro Surveill 18: 20406

12. Reusken C, Mou H, Godeke GJ, van der Hoek L, Meyer B, Müller MA, Haagmans B, de Sousa R, Schuurman N, Dittmer U, Rottier P, Osterhaus A, Drosten C, Bosch BJ, Koopmans M (2013) Specific serology for emerging human coronaviruses by protein microarray. Euro Surveill 18:20441

13. Stranieri A, Lauzi S, Giordano A, Paltrinieri S (2017) Reverse transcriptase loop-mediated isothermal amplification for the detection of feline coronavirus. J Virol Methods 243:105-108. https://doi. org/10.1016/j.jviromet.2017.01.009

14. Shirato K, Semba S, El-Kafrawy SA, Hassan AM, Tolah AM, Takayama I, Kageyama T, Notomi T, Kamitani W, Matsuyama S, Azhar EI (2018) Development of fluorescent reverse transcription loop-mediated isothermal amplification (RT-LAMP) using quenching probes for the detection of the Middle East respiratory syndrome coronavirus. J Virol Methods 258:41-48. https://doi.org/ 10.1016/j.jviromet.2018.05.006

15. Kumar P (2013) Methods for rapid virus identification and quantification. Mater Methods 3:207

16. Du L, Zhao G, Yang Y, Qiu H, Wang L, Kou Z, Tao X, Yu H, Sun S, Tseng CT, Jiang S, Li F, Zhou Y (2014) A conformation-dependent neutralizing monoclonal antibody specifically targeting receptorbinding domain in Middle East respiratory syndrome coronavirus spike protein. J Virol 88:7045-7053. https://doi.org/10.1128/jvi. 00433-14

17. Zuo B, Li S, Guo Z, Zhang J, Chen C (2004) Piezoelectric immunosensor for SARS-associated coronavirus in sputum. Anal Chem 76:3536-3540. https://doi.org/10.1021/ac035367b
18. Huang JC, Chang YF, Chen KH, Su LC, Lee CW, Chen CC, Chen YM, Chou C (2009) Detection of severe acute respiratory syndrome (SARS) coronavirus nucleocapsid protein in human serum using a localized surface plasmon coupled fluorescence fiber-optic biosensor. Biosens Bioelectron 25:320-325. https://doi.org/10.1016/j. bios.2009.07.012

19. Koo B, Jin CE, Lee TY, Lee JH, Park MK, Sung H, Park SY, Lee HJ, Kim SM, Kim JY, Kim SH, Shin Y (2017) An isothermal, labelfree, and rapid one-step RNA amplification/detection assay for diagnosis of respiratory viral infections. Biosens Bioelectron 90:187194. https://doi.org/10.1016/j.bios.2016.11.051

20. Jung IY, You JB, Choi BR, Kim JS, Lee HK, Jang B, Jeong HS, Lee K, Im SG, Lee H (2016) A highly sensitive molecular detection platform for robust and facile diagnosis of Middle East Respiratory Syndrome (MERS) Corona Virus. Adv Healthc Mater 5:2168-2173. https://doi.org/10.1002/adhm.201600334

21. Yang Z-H, Zhuo Y, Yuan R, Chai Y-Q (2015) An amplified electrochemical immunosensor based on in situ-produced 1-naphthol as electroactive substance and graphene oxide and Pt nanoparticles functionalized $\mathrm{CeO} 2$ nanocomposites as signal enhancer. Biosens Bioelectron 69:321-327. https://doi.org/10.1016/j.bios.2015.01. 035

22. Diouani MF, Helali S, Hafaid I, Hassen WM, Snoussi MA, Ghram A, Jaffrezic-Renault N, Abdelghani A (2008) Miniaturized biosensor for avian influenza virus detection. Mater Sci Eng C 28:580 583

23. Huang J, Xie Z, Luo S, Han J-H, Lee D, Chew CHC, Kim T, Pak JJ (2016) A multi-virus detectable microfluidic electrochemical immunosensor for simultaneous detection of H1N1, H5N1, and $\mathrm{H} 7 \mathrm{~N} 9$ virus using $\mathrm{ZnO}$ nanorods for sensitivity enhancement. Sens Actuators B Chem 228:36-42

24. Miodek A, Vidic J, Sauriat-Dorizon H, Richard C-A, Le Goffic R, Korri-Youssoufi H, Chevalier C (2014) Electrochemical detection of the oligomerization of PB1-F2 influenza a virus protein in infected cells. Anal Chem 86:9098-9105. https://doi.org/10.1021/ ac5018056

25. Huang J, Xie Z, Xie Z, Luo S, Xie L, Huang L, Fan Q, Zhang Y, Wang S, Zeng T (2016) Silver nanoparticles coated graphene electrochemical sensor for the ultrasensitive analysis of avian influenza virus H7. Anal Chim Acta 913:121-127. https://doi.org/10.1016/j. aca.2016.01.050

26. Wu Z, Zhou C-H, Chen J-J, Xiong C, Chen Z, Pang D-W, Zhang ZL (2015) Bifunctional magnetic nanobeads for sensitive detection of avian influenza A (H7N9) virus based on immunomagnetic separation and enzyme-induced metallization. Biosens Bioelectron 68: 586-592

27. Singh R, Hong S, Jang J (2017) Label-free detection of influenza viruses using a reduced graphene oxide-based electrochemical immunosensor integrated with a microfluidic platform. Sci Rep 7: 42771. https://doi.org/10.1038/srep42771

28. Huang H, Bai W, Dong C, Guo R, Liu Z (2015) An ultrasensitive electrochemical DNA biosensor based on graphene/Au nanorod/ polythionine for human papillomavirus DNA detection. Biosens Bioelectron 68:442-446. https://doi.org/10.1016/j.bios.2015.01. 039

29. Yanez-Sedeno P, Pingarron JM (2005) Gold nanoparticle-based electrochemical biosensors. Anal Bioanal Chem 382:884-886. https://doi.org/10.1007/s00216-005-3221-5

30. Yeh YC, Creran B, Rotello VM (2012) Gold nanoparticles: preparation, properties, and applications in bionanotechnology. Nanoscale 4:1871-1880. https://doi.org/10.1039/c1nr11188d

31. Wang D, Dou W, Zhao G, Chen Y (2014) Immunosensor based on electrodeposition of goldnanoparticles and ionic liquid composite for detection of Salmonella pullorum. J Microbiol Methods 106: 110-118. https://doi.org/10.1016/j.mimet.2014.08.016 
32. Eissa S, Abdulkarim H, Dasouki M, Al Mousa H, Arnout R, Al Saud B, Rahman AA, Zourob M (2018) Multiplexed detection of DOCK8, PGM3 and STAT3 proteins for the diagnosis of HyperImmunoglobulin E syndrome using gold nanoparticles-based immunosensor array platform. Biosens Bioelectron 117:613-619. https://doi.org/10.1016/j.bios.2018.06.058

33. Eissa S, Zourob M (2017) Aptamer- based label-free electrochemical biosensor array for the detection of total and glycated hemoglobin in human whole blood. Sci Rep 7(1):1016. https://doi.org/10. 1038/s41598-017-01226-0

34. Eissa S, Zourob M (2017) Competitive voltammetric morphine immunosensor using a gold nanoparticle decorated graphene electrode. Microchim Acta 184:2281-2289. https://doi.org/10.1007/ s00604-017-2261-9
35. Elshafey R, Tavares AC, Siaj M, Zourob M (2013) Electrochemical impedance immunosensor based on gold nanoparticles-protein $\mathrm{G}$ for the detection of cancer marker epidermal growth factor receptor in human plasma and brain tissue. Biosens Bioelectron 50:143149. https://doi.org/10.1016/j.bios.2013.05.063

36. Chen Z, Li L, Zhao H, Guo L, Mu X (2011) Electrochemical impedance spectroscopy detection of lysozyme based on electrodeposited gold nanoparticles. Talanta 83:1501-1506. https://doi.org/ 10.1016/j.talanta.2010.11.042 